\title{
Drug related esophagitis
}

RENÉ BEAUDRY, MD, FRCPC, CSPQ, FRANCO COLIZZA, MD

ABSTRACT: Esophageal injury after ingestion of various drugs often goes unrecognized. Two cases of tetracycline induced esophagitis are reported. The main presenting symptoms were odynophagia and dysphagia for both solids and liquids following the first two or three doses. Esophageal endoscopy revealed the presence of acute esophageal ulcers in both cases. Symptomatic relief was achieved by discontinuation of the drug and the use of viscous lidocaine and antacids. Recovery was complete within a few days. Recognition of this entity will help in its diagnosis and treatment, and should prevent further complications. Can J Gastroenterol 1989;3(4):135-137

Keys Words: Drug induced, Drug related, Esophagitis

\section{L'oesophagite médicamenteuse}

RESUME: Il est probable que les traumatismes oesophagiens survenant après l'ingestion de médicaments divers demeurent souvent méconnus. On rapporte deux cas d'oesophagite résultant de l'action de la tétracycline. Les principaux symptômes révélateurs étaient l'odynophagie et la dysphagie, pour les solides comme pour les liquides, après les deux ou trois premières doses. Une oesophagoscopie a révélé la présence d'ulcères oesophagiens aigus dans les deux cas. La cessation du médicament et l'administration de lidocaïne visqueuse et d'antiacides ont amené une résolution des symptômes. La guérison fut complète en quelques jours. Reconnaître cette entité aide à en poser le diagnostic, à choisir le traitement approprié et permet de prévenir toute autre complication.

Division of Gastroenterology, Department of Medicine, Faculty of Medicine; and Centre Hospitalier Universitaire de Sherbrooke, Sherbrooke, Québec

Correspondence and reprints: Dr René Beaudry, Faculté de Médecine, 3001, 12 ième Avenue

Nord, Sherbrooke, Québec JlH 5N4. Telephone (819) 563-5555 ext 4612

Received for publication February 21, 1989. Accepted June 1, 1989
A CUTE ESOPHAGITIS FOLLOWING ingestion of caustic substances is a well known entity. However, drug related esophagitis received attention only in 1970, when Pemberton (1) described the first case of potassium induced esophagitis. Since then, this type of injury has been recognized as a consequence of ingestion of several other medications. The following cases illustrate the usual presenting picture.

\section{CASE PRESENTATIONS}

Case one: A 23-year-old female patient presented with a four day history of dysphagia and odynophagia for both solids and liquids. Four days earlier, doxycycline, two tablets of $100 \mathrm{mg}$ each daily, had been prescribed for presumed chlamydial vaginitis, subsequently found to be associated with Torulopsis glabrata infection. Medication was stopped by the patient after two doses as she was unable to swallow the capsules.

Physical examination was unremarkable. No candida infection was present in the mouth or pharynx. 


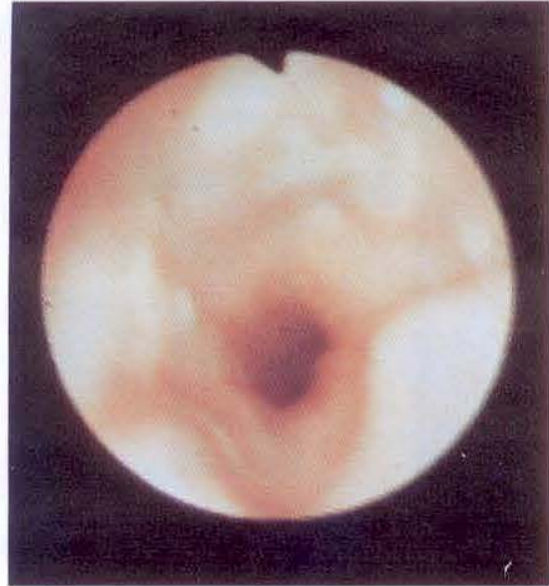

Figure 1) Esophageal circular superficial ulceration at $27 \mathrm{~cm}$

Esophageal endoscopy revealed superficial circular ulceration (Figure 1) starting at $27 \mathrm{~cm}$ from incisors for a distance of $4 \mathrm{~cm}$. Endoscopy was performed two days after the last dose of doxycycline. Antacids, viscous lidocaine and cessation of medication brought about complete resolution of symptoms within five days.

Case two: A 19-year-old male patient with facioscapulohumeral dystrophy presented with progressive odynophagia, more severe after ingestion of solids than liquids. History did not reveal symptoms suggestive of previous motility disorders.

Tetracycline $250 \mathrm{mg}$ tid had been started several days earlier because of bronchitis. Symptoms followed the ingestion of the third dose although the patient continued to take tetracycline for two more days, stopping only because swallowing the capsules was too painful. Further inquiries revealed poor intake of water with medication.

Endoscopy, $24 \mathrm{~h}$ after the last dose of tetracycline, revealed a longitudinal ulcer on the posterior esophageal wall extending from 32 to $40 \mathrm{~cm}$ from the incisors. At $30 \mathrm{~cm}$, a more superficial ulcer of $1 \mathrm{~cm}$ in diameter as well as a smaller one of $2 \mathrm{~mm}$ in diameter were also seen. Discontinuation of tetracycline, antireflux measures, antacids and viscous lidocaine before food ingestion led to complete relief of symptoms within three days. Repeat endoscopy was not clinically indicated in either patient and esophageal motility studies were not performed.

\section{DISCUSSION}

A brief delay between ingestion of medication and appearance of symptoms, as well as subsequent recovery upon stopping the implicated drug strongly support the diagnosis of drug induced esophagitis.

Several medications have been associated with such a complication. These include potassium tablets, quinidine, emepromium bromide, tetracycline and theophylline (2-6). In an extensive review of the literature, Kikendall and colleagues (7) reported 26 different drugs accounting for 221 cases of esophagitis. Antibiotics such as tetracycline, clindamycin, lincomycin and erythromycin lead the list with 96 cases. Emepromium bromide followed, a drug with anticholinergic properties used in the United Kingdom for nocturnal pollakiuria. Other drugs included slow release forms of potassium supplements, iron sulphate and succinate preparation, quinidine sulphate, aspirin and nonsteroidal anti-inflammatory drugs.

The age groups vary according to other underlying conditions. Thus, esophagitis associated with the use of emepromium occurs more frequently among the younger patients while potassium and quinidine related esophagitis has a higher incidence in older age groups.

\section{CLINICAL FEATURES}

The main presenting symptoms are odynophagia, sudden and sustained chest pain and dysphagia. Less frequently, nonspecific symptoms such as weight loss, abdominal pain and hematemesis are reported (7). Circumstances surrounding the ingestion of the medication is a key diagnostic element as $40 \%$ of patients report the ingestion of the drug with only a small amount of liquid or prior to retiring to bed. Symptoms usually appear within a few days of initiation of therapy and generally within a month (8). Symptoms rarely follow cessation of the drug.

Radiologic examination of the esophagus is not usually helpful in the diagnosis except in advanced lesions. However, double contrast studies may be more beneficial (9). Barium swallow studies occasionally demonstrate find- ings suggestive of esophageal cancer $(2,7,10)$, especially with quinidine.

Endoscopic examination of the esophagus confirms the diagnosis. Injuries are usually found in the mid-portion of the esophagus, neighbouring the normal aortic arch imprint (8).

Ulcerations vary in size and are surrounded by an inflammatory area which may spread over several centimetres. Strictures may also be encountered and more frequently when dealing with injuries caused by slow release potassium supplements or quinidine. Biopsies reveal acute inflammatory infiltrates with edema and ulcerations and without viral inclusion bodies or mycelium.

For the majority of patients, outcome is benign with complete regression of symptoms within a week. Injuries caused by potassium supplement tablets seem to be associated with a greater frequency of complications. Of 16 reported cases, 13 developed complications, stricture being the most common. Four cases resulted in death; two following acute bleeding and two subsequent to mediastinal perforation $(7,11)$.

\section{MECHANISMS}

The mechanisms involved in drug related esophagitis are multifactorial, involving anatomic and functional aspects of the esophagus as well as particular properties of each drug. It is often assumed that after the ingestion of a medication, the tablet quickly reaches the stomach. However, Evans and Roberts (12) have demonstrated that such is not always the case. In 57 patients who swallowed barium tablets of a size comparable to aspirin, stasis in the esophagus could last for periods of up to 5 mins when taken with a small amount of liquid. Delay of transit was found not only in patients with esophageal abnormalities such as hiatal hernia or motility disorders but also in a great number of normal subjects (36 of 57 patients). After studying the esophageal transit time with various drugs, Hey and co-workers (13) recommended to always swallow the tablets with a minimum of $100 \mathrm{~mL}$ of liquid and to remain in a standing position for a period of at least $90 \mathrm{~s}$. 
Esophageal stasis of drugs is favoured by the presence of a stricture, an external compression of the esophagus or an intrinsic motility disorder. The physiologic narrowing occurring across the aortic arch could be responsible for the high occurrence of lesions in that portion of the esophagus (8).

Several other mechanisms have been postulated. The physical and chemical properties of the drugs involved are certainly an important factor to consider. Tetracyclines and doxycyclines have corrosive properties, developing an acidic $\mathrm{pH}$ after local dissolution. However, most drugs have a

\section{REFERENCES}

1. Pemberton J. Oesophageal obstruction and ulceration caused by oral potassium therapy. Br Heart J 1970;32:267-8.

2. Teplick JG, Teplick SK, Ominsky SH, Haskin ME. Esophagitis caused by oral medication. Radiology 1980;1 34:23-5.

3. Mason S], O'Meara TF. Drug-induced esophagitis. J Clin Gastroenterol 1981;3:115-20.

4. Collins FJ, Matthews HR, Baker SE, Strakova JM. Drug-induced oesophageal injury. Br Med ] 1979;1.1673-6.

5. Crowson TD, Head LH, Ferrante WA. Esophageal ulcers associated with higher pH suggesting other underlying mechanisms. Emepronium bromide has inherent caustic properties unrelated to $\mathrm{pH}$. When taken with a very small quantity of liquid, these tablets tend to be extremely adherent to the esophageal wall. Local release of potassium tablets can cause local spasms leading to regional infarcts and consequently bringing about hemorrhage and ulcerations (8). Mechanisms of injury for other medications are still unknown.

\section{TREATMENT}

Treatment is usually simple. Recognition of the condition and immediate

tetracycline therapy. JAMA 1976;235:2747-8.

6. Enzenauer RW, Bass JW, McDonnell JT. Esophageal ulceration associated with oral theophylline. N Engl J Med 1984;310:261.

7. Kikendall JW, Friedman AC, Oyewole MA, Fleishcher D, Johnson LF. Pillinduced esophageal injury. Dig Dis Sci 1983;28:174-81.

8. Becouarn Y, Lamouliatte H, Quinton A. Lésions aigues de l'oesophage d'origine médicamenteuse. Gastroentérol Clin Biol 1983;7:868-76.

9. Creteur V, Laufer I, Kressel HY, et al. Drug-induced esophagitis detected by cessation of the medication constitute the first step. Antacids combined with local anesthetics help relieve symptoms during the acute period.

However, simple maneuvres, such as taking sufficient liquid with the tablets or avoiding ingestion prior to bed rest, will help to reduce incidence of complications. A switch to the liquid forms of certain drugs with potential corrosive properties, when possible, is recommended for patients with motility disorders or esophageal stricture. Thus, recognition of this drug induced entity will facilitate diagnosis, treatment and prevention of its complications.

double-contrast radiography. Radiology 1983;147:365-8.

10. Wong RKH, Kikendall JW, Dachman AH. Quinaglute-induced esophagitis mimicking an esophageal mass. Ann Intern Med 1986;105:62-3.

11. Rosenthal T, Adar R, Militianu J, Deutsch V. Esophageal ulceration and oral potassium chloride ingestion. Chest 1974;65:463-5.

12. Evans KT, Roberts GM. Where do all the tablets go? Lancet 1976;ii:1237-9.

13. Hey H, Jorgensen F, Sorensen K, Hasselbalch $\mathrm{H}$, Wamberg T. Oesophageal transit of six commonly used tablets and capsules. Br Med J 1982;285:1717-9. 




The Scientific World Journal
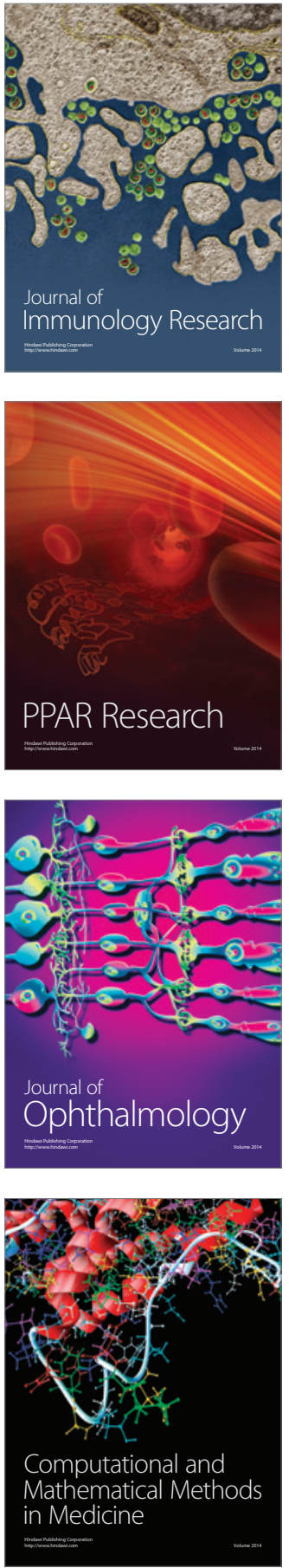

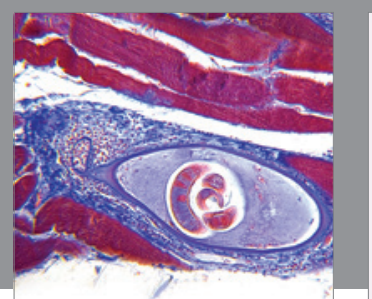

Gastroenterology Research and Practice

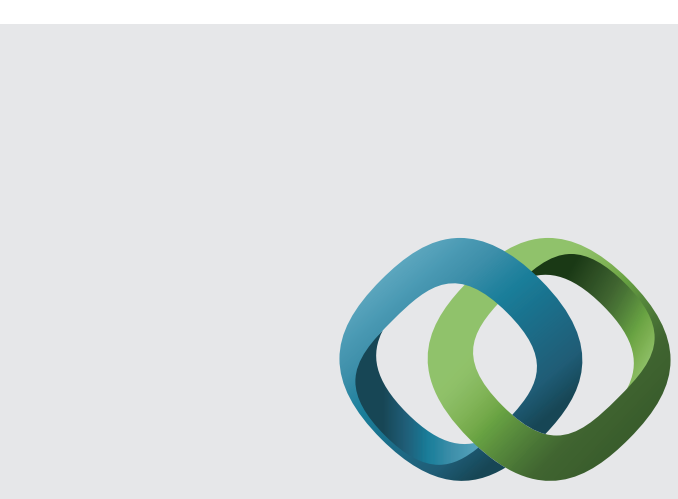

\section{Hindawi}

Submit your manuscripts at

http://www.hindawi.com
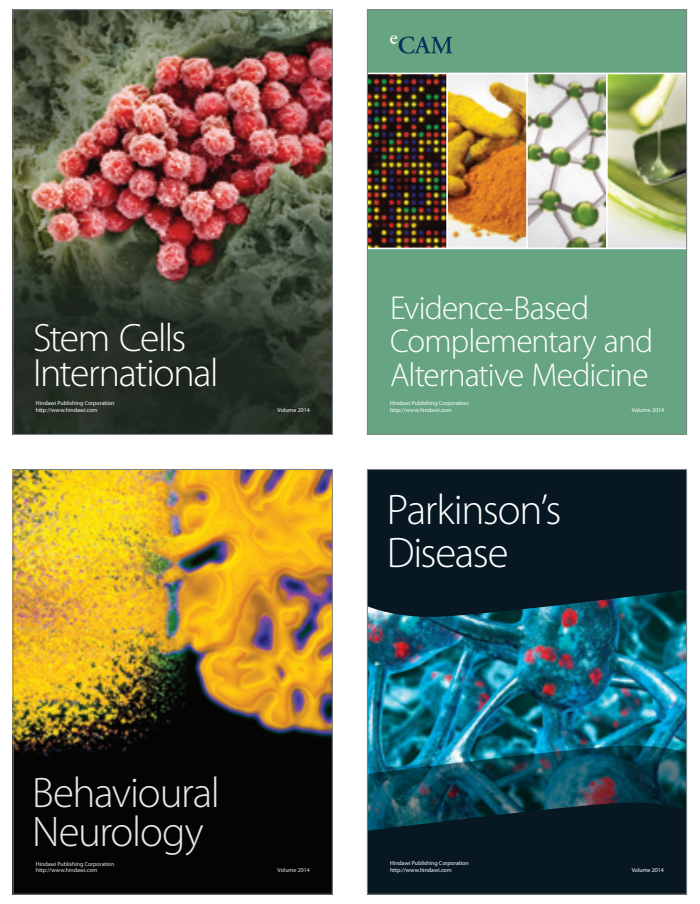


Disease Markers
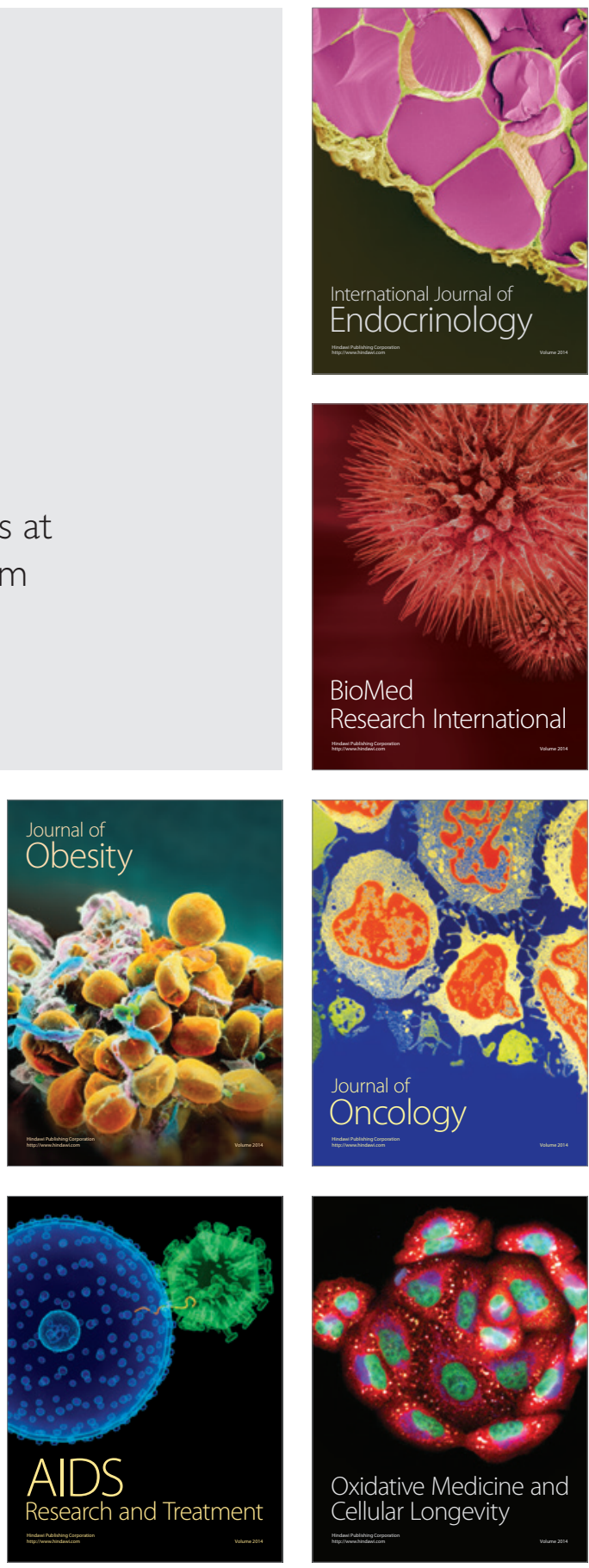